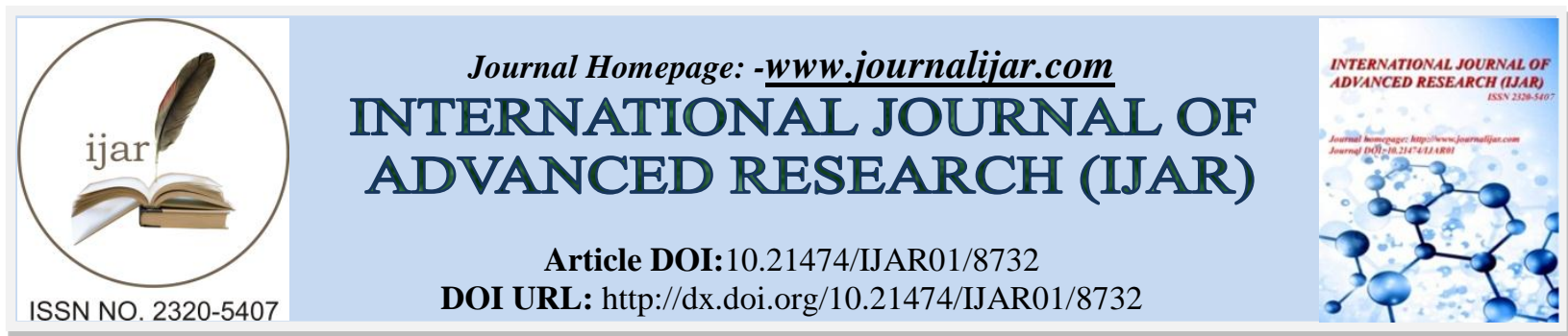

RESEARCH ARTICLE

\title{
NATURAL ACID CATALYZED SYNTHESIS OF SCHIFF BASE FROM SALICYLALDEHYDE AND $P$ - TOLUIDINE AND ITS ANTIMICROBIAL POTENTIAL.
}

A. Subathra and Dr. R. Ajitha.

Department of Chemistry and Research centre, Women's Christian college, Nagercoil.

\section{Manuscript Info}

\section{Manuscript History}

Received: 18 January 2019

Final Accepted: 20 February 2019

Published: March 2019

Key words:-

Eco-friendly process; Natural acid catalyst; Solvent free synthesis; Schiff base; Antimicrobial studies.

\begin{abstract}
One of the major category of compounds in medicinal chemistry related to Schiff base, which are known for their versatile pharmacological activity and well known drugs are isoniazid and pyrazinamid. Schiff bases have been synthesized by the condensation of primary amine with aldehyde under organic solvent free condition. Nowadays the solvent-free approach to the synthesis of molecules becomes an attractive one since the majority of solvents are either toxic or flammable and adds considerably to the cost of overall synthesis. In many cases, the solvent-free approach improves selectivity, reduces reaction time, and simplifies separation and purification of products than the conventional methods. Natural acid is non-polluting and does not employ any lethal materials, quantifying if as a green approach for the synthesis of Schiff bases. Thus, the presents study uses kaffir lime as a natural acid catalyst for the synthesis of Schiff base from salicylaldehyde and p-toluidine. The synthesized product was characterized by UV-Visible, FT-IR, ${ }^{1} \mathrm{H}-\mathrm{NMR}$ spectral techniques. The antimicrobial potential of this Schiff base is tested against bacteria and fungi. This eco-friendly reaction has many advantages like economical, environmental, mild reaction conditions and simple work-up with high product yield.
\end{abstract}

Copy Right, IJAR, 2019,. All rights reserved.

\section{Introduction:-}

The beginning of green chemistry is frequently considered as a response to the need to reduce the damage of the environment by man-made materials and the processes used to produce them. A quick view of green chemistry issues in the past decade demonstrates many methodologies that protect human health and the environment in an economically beneficial manner [1]. Green Chemistry is not different from traditional chemistry in as much as it embraces the same creativity and innovation than has always been central to classical chemistry $[2,3]$. According to the principles of green chemistry, a threat can be eliminated in a simpler way, by applying safe raw materials for production process [4]. Organic synthetic procedures use organic solvents like benzene and chlorinated hydrocarbons, which have created havoc to the environment because of their toxic and volatile nature [5]. Solventfree reactions usually need shorter reaction times, simpler reactors, resulting simpler and more efficient work up procedures, more improved selectivities and easier separations and purifications than conventional solvents [6,7]. The role of naturally available fruit juice in organic synthesis has attracted the interest of chemists, particularly from

Corresponding Author:-A. Subathra.

Address:-Department of Chemistry and Research centre, Women's Christian college, Nagercoil. 
the view of green chemistry. This shows versatile synthetic applications of fruit juice as a biocatalyst in chemical transformation [7].

The class of organic compounds containing the azomethine $(-\mathrm{HC}=\mathrm{N}-)$ group in their structure is called imine compounds or alternatively a Schiff base [8]. It was first prepared by German Hugo Schiff, these compounds were prepared by condensation reactions of carbonyl (aldehyde or ketone) with primary amines a companied with the elimination of water molecule [9]. The common structural feature of these compounds is the azomethine group with a general formula $\mathrm{RHC}=\mathrm{N}-\mathrm{R} 1$, where $\mathrm{R}$ and $\mathrm{R} 1$ are alkyl, aryl, cyclo alkyl or heterocyclic groups which may be variously substituted [10]. Aromatic Schiff bases are more stable and more easily synthesized than alkyl substituted compound [11]. Carbon-nitrogen double bond provides a significant contribution in various progresses of chemical sciences. Schiff-base compounds have been potentially used as fine chemicals and medical substrates [12]. They have been reported to exhibit antimicrobial, antibacterial, anti-inflammatory, antimalarial, antioxidant, antiproliferative, antiviral, antipyretic, antifungal, antitumor, analgesic, anticonvulsant, urease inhibitory, and anticancer activities $[13,14]$.

Most organic reactions utilized organic solvents and acids in which some are curse for environment because of this reason we did not use any organic solvent and acid [15]. In this method salicylaldehyde is reacted with $p$-toluidine in the presence of natural acid extracted from kaffir lime to give Schiff base. The kaffir lime (Citrus hystrix DC, Rutaceae) is also known as combava, kieffer lime, limau purut, jeruk purut or makrut lime, Kabuyao (Cabuyao). Kaffir lime has great potential in research and commercialization for aromatherapy and spa practices, solution for insect repellent, making shampoo, antioxidants compound and beauty product [16]. The chemical constituents found in this plant are alkaloids, flavonoids, phenolics and tannins. Coumarins and glycosides were also isolated and identified [17]. The Schiff base synthesised from kaffir lime is identified by various spectroscopic techniques such as UV-Visible, FT-IR and ${ }^{1}$ H-NMR. The synthesised products also showed significant antibacterial, antifungal activities.

\section{Materials and Methods:-}

Fresh and ripened kaffir lime was obtained from the local market. Salicylaldehyde and $p$-toluidine used for the synthesis of Schiff base were procured from Merck.

\section{Preparation of catalyst}

Fresh kaffir lime was taken and washed it thoroughly with distilled water and cut by using a knife and then pieces were pressed manually. Then the extract was filtered through cotton cloth to remove solid material and to get clear extract which was used as a catalyst.

\section{Characterization Techniques}

The absorption spectrum of Schiff base in ethanol was carried out using Shimadzu UV-1800 spectrophotometer. FTIR analysis of the Schiff base in ethanol was carried out through the potassium bromide (KBr) pellet (FTIR grade) method in 1:100 ratio and spectrum was recorded using Shimadzu IR Affinity-1. Fourier transform infrared spectrophotometer with the range of $4000-400 \mathrm{~cm}^{-1}$ at the resolution of $4 \mathrm{~cm}^{-1}$. ${ }^{1} \mathrm{H}-\mathrm{NMR}$ (nuclear magnetic resonance) spectra of Schiff base was recorded on a Brucker Avance III, $400 \mathrm{MHz}$ spectrometer in the DMSO solvent using tetramethylsilane as an internal reference.

\section{Synthesis of Schiff base from kaffir lime extract}

The equimolar amount of salicylaldehyde $(0.1 \mathrm{~mol})$ with $p$-toluidine $(0.1)$ was taken in a beaker. Add $1 \mathrm{ml}$ of kaffir lime extract to the mixture and then kept for 5-10 minutes. Then the mixture was stirred for 10 minutes at room temperature, pale yellow solid crude product was formed. After completion of the reaction, the product was washed with distilled water and purified by recrystallization with minimum amount of ethanol. The recrystallized sample was characterized by UV-Visible, FT-IR and ${ }^{1} \mathrm{H}-\mathrm{NMR}$ spectral techniques.

\section{Biological Assay}

The synthesized Schiff base is screened for antibacterial and antifungal activity. These antimicrobials were grown in LB broth for $24 \mathrm{hrs}$. Approximately $20 \mathrm{ml}$ of molten and cooled Muller Hinton agar was poured into the Petri dishes. The tested organisms were swapped over the agar medium and the Schiff base containing disks were kept over the medium using sterile forceps. Antimicrobial activity was evaluated by measuring the zone of inhibition for the test organisms. The diameters of zones were measured to the nearest millimetre with verniercalipers. 


\section{Results and Discussion:-}

It was observed that Schiff base have been synthesized by the condensation of salicylaldehyde with $p$-toluidine in the presence of kaffir lime extract. The carbonyl group in the salicylaldehyde is electrophilic in nature whereas amino group in $p$-toluidine is nucleophilic. In the condensation reaction first step is the protonation of carbonyl oxygen. In this method natural acid found in kaffir lime extract was used as a catalyst to protonate carbonyl oxygen and under solvent free condition good yield was obtained. The product is characterized by UV-Visible, FT-IR and ${ }^{1} \mathrm{H}-\mathrm{NMR}$ spectral analysis.<smiles>Cc1ccc(/N=C/c2ccc(-c3ccc(C)cc3)cc2O)cc1</smiles>

Scheme 1:-Synthesis of Schiff base from salicylaldehyde and $p$-toluidine

\section{Analysis of UV-Visible Spectra}

The formation of Schiff base using kaffir lime extract is preliminary confirmed by UV-Visible spectrophotometric analysis. The absorption spectrum of Schiff base is carried out in ethanol. The Schiff base shows an absorption maximum at $298 \mathrm{~nm}$. The higher energy band appearing at $298 \mathrm{~nm}$ is attributed to $\pi-\pi^{*}$ transition of the azomethine group. The UV-Visible spectrum of synthesised Schiff base is given in Fig.1.

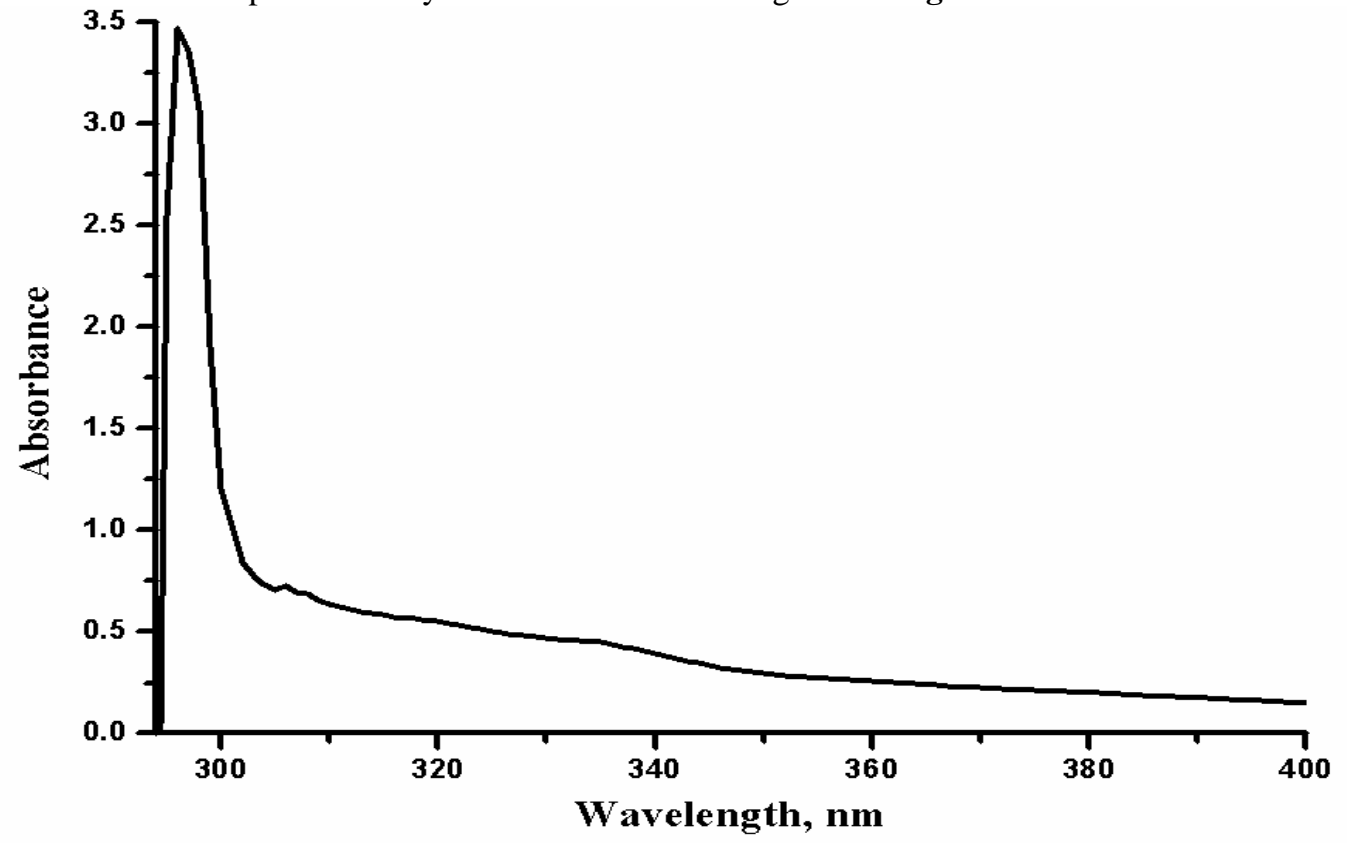

Fig 1:-UV-Visible spectrum of Schiff base from salicylaldehyde and $p$-toluidine with kaffir lime

\section{Analysis of FT-IR Spectra}

The FT-IR spectrum of Schiff base synthesised from salicylaldehyde and $p$-toluidine with kaffir lime extract shows bands at 3341, 3291, 2922, 2859, 2719, 2679, 2596, 1737, 1587, 1607, 1307, 1278, 970, 902, 844, $686 \mathrm{~cm}^{-1}$ respectively. The FT-IR spectrum of the synthesised Schiff base shows a band around $3341 \mathrm{~cm}^{-1}$ is due to the stretching vibration of $\mathrm{O}-\mathrm{H}$. The weak band at $3291 \mathrm{~cm}^{-1}$ is due to the $\mathrm{C}-\mathrm{H}$ stretching of aromatic ring. Absorption bands at 2922, 2859 and $2719 \mathrm{~cm}^{-1}$ corresponds to the C-H stretching of methyl group. The presence of weak band at $2679,2596 \mathrm{~cm}^{-1}$ corresponds to the aldehyde C-H stretching. The IR band at $1737 \mathrm{~cm}^{-1}$ is due to the presence of azomethine group, this confirms the formation of Schiff base. The IR band at $1607,1587 \mathrm{~cm}^{-1}$ is due to the stretching vibration of aromatic $\mathrm{C}=\mathrm{C}$. The band around $1307 \mathrm{~cm}^{-1}$ is the $\mathrm{C}-\mathrm{H}$ bending of alkyl group. Absorption bands at $1278 \mathrm{~cm}^{-1}$ is due to C-N stretching vibration. Aromatic C-H bending vibrations occur at 970, 902 and 844 
$\mathrm{cm}^{-1}$ respectively. The band at $686 \mathrm{~cm}^{-1}$ is due to C-C bending of aromatic ring. The IR spectrum of synthesised Schiff base is given in Fig.2.

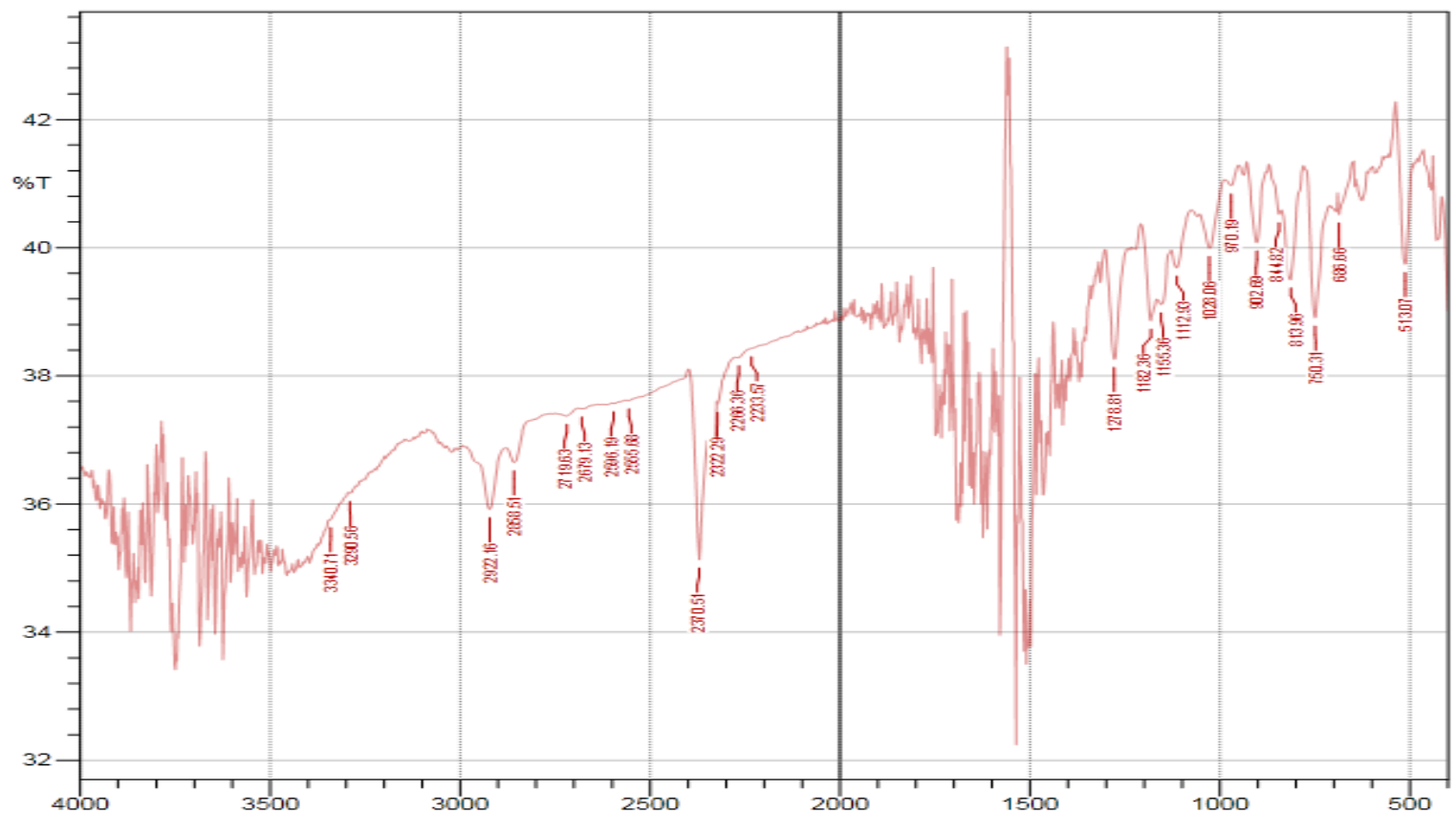

Fig 2:-FT-IR spectrum of Schiff base from salicylaldehyde and $p$-toluidine with kaffir lime

\section{Analysis of ${ }^{1} \mathrm{H}-\mathrm{NMR}$ spectra}

The ${ }^{1} \mathrm{H}$ NMR spectrum of the synthesised Schiff base recorded in DMSO solution shows signals at 8.94, 7.63, 7.39, $7.32,7.26,3.40,2.34 \delta$ respectively. A singlet at $8.94 \delta$, equivalent to $1 \mathrm{H}$, is due to $-\mathrm{CH}=\mathrm{N}$ - proton. Aromatic protons appear between 7.26-7.63 $\delta$. A singlet at $13.24 \delta$, equivalent to $1 \mathrm{H}$ is due to $\mathrm{O}-\mathrm{H}$ proton. A singlet at $2.34 \delta$, equivalent to $3 \mathrm{H}$, represents the methyl protons. The ${ }^{1} \mathrm{H}$ NMR spectrum of synthesised Schiff base is given in Fig.3.

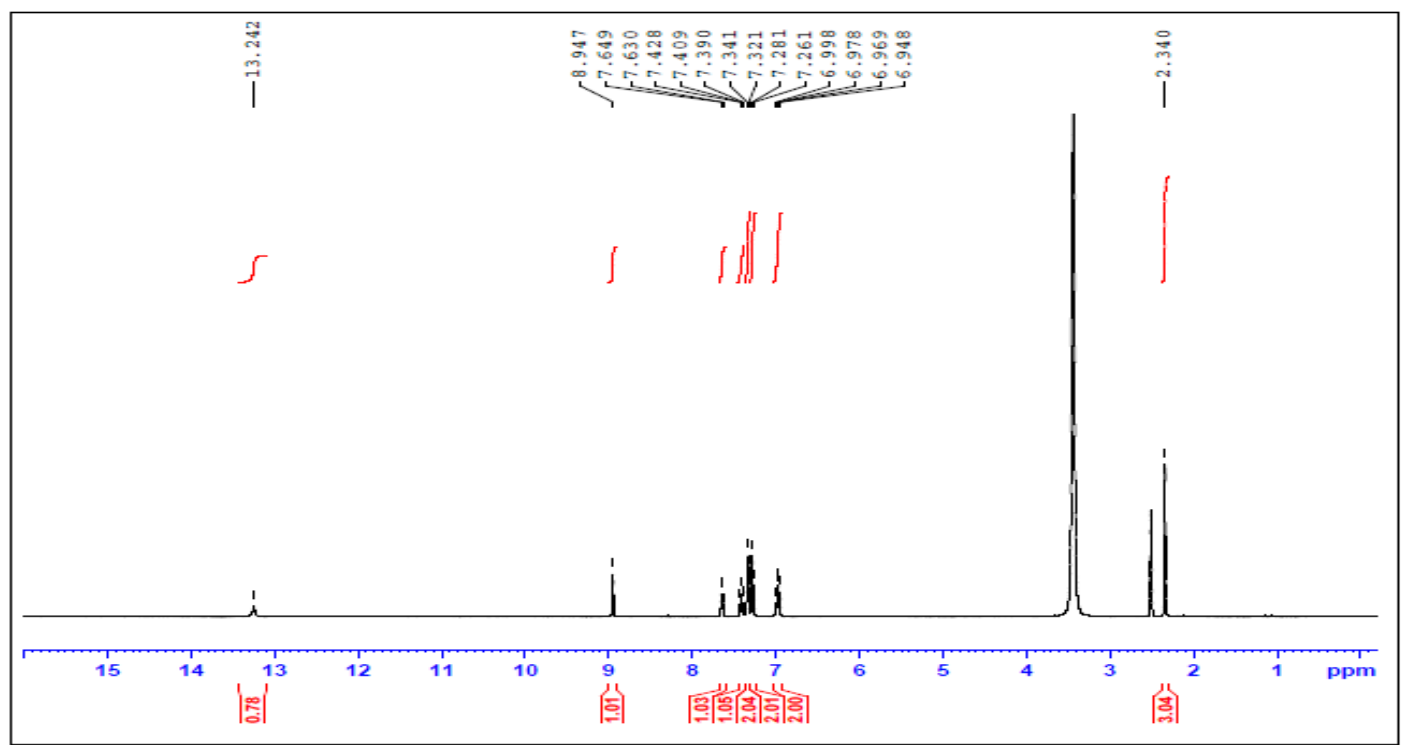

Fig 3:-H-NMR spectrum of Schiff base from salicylaldehyde and $p$-toluidine with kaffir lime

\section{Antibacterial Activity}

Antibacterial activity of the synthesised schiff base is performed against five bacteria viz. Bacillus subtilis, Staphylococcus aureus, Pseudomonas aeruginosa, Streptococcus sp and Escherichia coli. It shows good activity 
against on Bacillus subtilis, Staphylococcus aureus, Pseudomonas aeruginosa, Streptococcus sp, Escherichia coli (Table 1). Thus the Schiff base synthesised from salicylaldehyde and $p$-toluidine using kaffir lime extract may have a potential use in the biomedical applications due to its antibacterial activity.

Table 1:-Antibacterial activity of Schiff base synthesised from salicylaldehyde and $p$-toluidine with mosambi extract

\begin{tabular}{|l|l|l|}
\hline Microbes & Activity & Std.Value \\
\hline Bacillus subtilis & 10 & 21 \\
\hline Staphylococcus aureus & 17 & 33 \\
\hline Pseudomonas aeruginosa & 11 & 26 \\
\hline Streptococcus sp & 8 & 10 \\
\hline Escherichia coli & 13 & 16 \\
\hline
\end{tabular}

\section{Antifungal Activity}

Antifungal activity of the synthesised Schiff base is tested against three fungi viz. Pencilium notatum, Aspergillus niger and Aspergillus flavus. It shows good activity against on Pencilium notatum, Aspergillus niger, Aspergillus flavus (Table 2). Thus the Schiff base synthesised from salicylaldehyde and $p$-toluidine using kaffir lime extract may have a potential use in the biomedical applications due to its antimicrobial activity.

Table 2:-Antifungal activity of Schiff base synthesised from salicylaldehyde and $p$-toluidine using kaffir lime extract

\begin{tabular}{|l|l|l|}
\hline Microbes & Activity & Std.Value \\
\hline Pencilium notatum & 9 & 14 \\
\hline Aspergillus niger & 11 & 18 \\
\hline Aspergillus flavus & 13 & 19 \\
\hline
\end{tabular}

\section{Conclusion:-}

The present study concentrates on the importance of fruit juice in organic transformations with natural and biocatalyst exclusivity. An eco-friendly method for the synthesis of Schiff base from salicylaldehyde and $p$-toluidine using kaffir lime extract has been investigated. The role of natural acid catalyst like kaffir lime extract in the synthesis of biologically active molecules has been well demonstrated. The synthesised Schiff base shows an absorption maximum at $298 \mathrm{~nm}$. The FT-IR band at $1737 \mathrm{~cm}^{-1}$ is due to the presence of azomethine group. The ${ }^{1} \mathrm{H}-$ NMR signal at $8.94 \delta$ is attributed to $-\mathrm{CH}=\mathrm{N}$ - proton, this confirms the formation of Schiff base. This solvent-free approach is non-polluting and does not employ any toxic materials, quantifying it as a green approach for the synthesis of Schiff bases. In addition to this, compared to traditional methods, this new method is cleaner, safer and more eco-friendly, involving mild reaction conditions and simple workup. The biological activity results prove that the synthesised Schiff base can be used for the treatment of diseases caused by microbes. Such schiff bases can be good lead compounds for the development of new drug entities in future.

\section{References:-}

1. Wardencki, w., Curylo, J., Namiesnik, J., Green chemistry-current and future issues, Polish Journal of Environmental Studies, 2005, 14, 389-395.

2. Manmohan, S., Arjun, S., Khan, S.P., Eram, S., Sachan, N.K., Green chemistry potential for past, present and future perspectives, International Research Journal of Pharmacy, 2012, 3, 31-36.

3. Rani, B., Maheshwari, R., Chauhan, A.K., Singh, U., Potentiality of green chemistry for future perspectives, International Journal of Pharmaceutical and Chemical Sciences, 2012, 1, 97-104.

4. Ravichandran, S., Implementation of green chemistry principles into practice, International Journal of ChemTech Research, 2011, 3, 1046-1049.

5. Rao, V.K., Reddy, S.S., Krishna, B.S., Naidu, K.R.M., Raju, C.N., Ghosh, S.K., Synthesis of schiff's bases in aqueous medium: a green alternative approach with effective mass yield and high reaction rates, Green Chemistry Letters and Reviews, 2010, 3, 217-223.

6. Chawla, A., Sukhmandeep, K., Kuldeep, K., Chawla, P., Dhawan, R.K., A current review of synthesis methods of schiff bases, SK International Journal of Multidisciplinary Research Hub, 2015, 2, 10-18.

7. Patil, S., Jadhav, S.D., Patil, U.P., Natural acid catalyzed synthesis of schiff base under solvent-free condition: As a green approach, Archives of Applied Science Research, 2012, 4, 1074-1078. 
8. Vijayalakshmi, K., Punitha, N., Mangalam, M., Selvan, S.A., Green synthesis of schiff base and its complex using natural acid catalyst under microwave condition, International Journal of Nano Corrosion Science and Engineering, 2015, 2, 31-36.

9. Deivanayagam, P., Bhoopathy, R.P., Thanikaikarasan, S., Synthesis, characterization, antimicrobial, analgesic and CNS studies of Schiff base Cu (II) complex derived from 4-choro-o-phenylene diamine, International Journal of Advanced Chemistry, 2014, 2, 166-170.

10. Ashraf, M.A., Mahmood, K., Wajid, A., Synthesis, characterization and biological activity of schiff bases, International Conference on Chemistry and Chemical Process, 2011, 10, 1-7.

11. Elmali, A., Kabak, M., Elerman, Y., Keto-enol tautomerism, conformations and structure of N-(2-hydroxy-5methylphenyl), 2-hydroxy benzaldehyde imine, Journal of Molecular Structure, 2000, 477, 151-158.

12. Ramadhan, U.H., Haddad, H.M., Ezaria, Z.G., Synthesis of schiff bases complexes as anti-inflammatory agents, World Journal of Pharmacy and Pharmaceutical Sciences, 2016, 5, 98-108.

13. Muzammil, K., Trivedi, P., Khetani, D.B., Synthesis and characterization of schiff base m-nitro aniline and their complexes, Research Journal of Chemical Sciences, 2015, 5, 52-55.

14. Bader, N.R., Applications of schiff's bases chelates in quantitative analysis-A review, Rasayan J. Chem, 2010, 3, 660-670.

15. Arafa, W.A.A., Shaker, R.M., Facile green chemistry approaches towards the synthesis of bis-Schiff bases using ultrasound versus microwave and conventional method without catalyst, General papers, 2016, 3, 187201.

16. Wahab, A., Haider, S.S., Mahmood, I., Mahmood, T., Sherwani, S.K., Kanwal, S., Synthesis of schiff bases from natural products and their remarkable antimicrobial and antioxidant activity, FUUAST J. BIOL, 2014, 4, 27-32.

17. Kasuan, N., Muhammad, Z., Yusoff, Z., Rahiman, M.H.F., Taib, M.N., Haiyee, Z.A., Extraction of Citrus hystrix D.C (Kaffir lime) essential oil using automated steam distillation process: Analysis of volatile compounds, Malaysian Journal of Analytical Sciences, 2013, 17, 359-369. 